\title{
A VINCULAÇÃO DOS PRECEDENTES JUDICIAIS EM SEDE DO EXERCÍCIO DA JURISDIÇÃO CONSTITUCIONAL: DEMOCRACIA E OS OBTER DICTA ILEGÍTIMOS
}

\section{Rodrigo Brunieri Castilho ${ }^{1}$}

RESUMO: O presente trabalho visa analisar a questão dos pronunciamentos judiciais ilegítimos, dada a compreensão e função da jurisdição constitucional, no bojo das formas de controle de constitucionalidade e da vinculação das decisões judiciais. Apresenta-se a tensão que isto pode trazer para a manutenção da Constituição, seus princípios e a segurança da ordem jurídica do Estado. A metodologia utilizada foi a teórica bibliográfica.

PALAVRAS-CHAVE: constitucionalismo; jurisdição; decisões; vinculação; ilegítimo.

\section{THE BINDING OF JUDICIAL PRECEDENTS IN HEADQUARTERS OF CONSTITUTIONAL JURISDICTION: DEMOCRACY AND ILLEGITIMATE OBTER DICTA}

\begin{abstract}
This paper aims to analyze the issue of illegitimate judicial pronouncements, given the understanding and function of constitutional jurisdiction, in the midst of the forms of constitutionality control and binding of judicial decisions. It presents the tension that this can bring to the maintenance of the Constitution, its principles and the security of the State's legal order. The methodology used was the bibliographic theory.
\end{abstract}

KEYWORDS: constitutionalism; jurisdiction; decisions; binding; illegitimate.

\section{INTRODUÇÃO}

O presente trabalho apresenta como objetivo geral a análise da jurisdição constitucional, o papel que ela desempenha e os pronunciamentos judiciais ilegítimos.

Tem-se como justificativa lançar luzes sobre as crescentes e inapropriadas manifestações, por vezes numa linha tênue de separação das funções jurisdicionais atribuídas aos tribunais, especialmente do Supremo Tribunal Federal, que desempenha o papel de corte constitucional por excelência, e os demais poderes.

A conjectura dos precedentes judiciais irmanados pelos tribunais de cúpula, pelos quais todos demais tribunais ficam por eles vinculados, atrelados ao modelo brasileiro de

\footnotetext{
${ }^{1}$ Doutorando em Direito Constitucional pela FADISP. Mestre em Direito Processual e Cidadania pela UNIPAR. Professor da graduação em Direito da UNIPAR, campus Toledo. Advogado no Paraná.
} 
controle de constitucionalidade, tanto de modo concreto como abstrato, intensificam a constatação da nocividade dos pronunciamentos judiciais ilegítimos.

No afã de tornar claro que os órgãos de Estado devem estritamente estribar suas funções sem interferir nas funções um dos outros é que se visa apresentar neste estudo.

\section{JURISDIÇÃO CONSTITUCIONAL}

Pode-se considerar a Segunda Grande Guerra Mundial como marco para sociedade. Tanto quanto do ponto de vista social, político e principalmente jurídico (ABBOUD, 2016, p. $103)$.

Isto pois, a jurisdição constitucional surge como caráter revolucionário contra patologias de excesso de poder, como forma de contenção e racionalização para a própria preservação da Constituição.

Haja vista a necessidade de saber-se a qual Poder recorrer contra as investidas ao texto constitucional, dado abrigar direitos conquistados a duras penas, tem-se o constitucionalismo, como movimento capaz de reunir características e preceitos de proteção aos direitos humanos e fundamentais de um Estado (ALVIM, 2014, p. 57-58).

Como acentua Mauro Cappelletti (1992, p.13):

Acima da lei entendida como pura expressão de uma vontade soberana, centralizada na vontade do Estado, jus quia jussum, há um valor, porém também ele historicamente condicionado e, por isto, relativo, mas menos relativo que a lei ordinária, e subtraído aos volúveis comportamentos de passageiras maiorias governamentais ou parlamentares. E aquele valor tem o seu juiz, "Hüter der Verfassung", que lhe garante a efetividade.

Nesse sentido, através de um processo contínuo as Constituições foram se desprendendo da potencialidade inerente aos seus postulados, como a soberania de um povo, dos direitos fundamentais e a divisão de poderes, vez que somente assim a supremacia jurídica da Constituição poder-se-ia erigir efetivamente na vida de uma sociedade (REYES, 2019, p. 03).

\section{O PAPEL DA JUSTIÇA CONSTITUCIONAL}


Sustenta-se como corolário natural de limitação de um Estado absoluto, uma regra segundo a qual o comportamento de todos os demais poderes deve basear-se sobre uma norma jurídica prévia (ROLLA, 2001, p.01).

Outrossim, como aponta Giancarlo Rolla (2001, p. 02), a Justiça Constitucional diferencia-se do controle de constitucionalidade, posto que este é exercido por um algum órgão externo ao procedimento legislativo, balizado pela imparcialidade e profissionalidade, e seu desenvolvimento tem lugar segundo um procedimento com caracteres típicos de um processo e sua conclusão dá-se segundo técnicas própria de um método jurídico.

De igual modo disserta Renato Gugliano Herani, ao dizer que a doutrina clássica não comunga da ideia de reduzir a justiça constitucional apenas ao controle de constitucionalidade, de visão keselniana, posto se "confirmar um poder estatal soberano que provoca a revisão, para não dizer a superação da vetusta tripartição dos poderes clássicos estatais" (HERANI, 2015, p. 105).

Desse modo, objetiva-se favorecer a coerência do sistema, não somente em relação as possíveis antinomias das normas internas do ordenamento jurídico, como também dar autenticidade às normas constitucionais, traçando teses e perfazendo seu alinhamento entre as decisões dos tribunais a despeito dessas interpretações.

Nesse jaez, a Justiça Constitucional opera uma função eminentemente asseguradora do texto constitucional, razão pela qual deve individualizar entre as amplas possibilidades de construções de significados da norma primaria, aquela que seja mais adequada e coerente com as próprias disposições constitucionais. Dessarte, opera-se a função nomofilácica na Corte Constitucional.

\section{TENSÃO ENTRE A DEMOCRACIA E A JUSTIÇA CONSTITUCIONAL}

O futuro da Justiça Constitucional, tendo em vista seu caráter indissociável da Constituição, e assim sendo, do seu próprio futuro, arvora-se no Estado Constitucional de direito.

Isto pois, os perigos que rondam o Estado, representados pelos fundamentalismos identitários, os populismos e nacionalismos excludentes, são filtrados e protegidos pela justiça constitucional, que consequentemente protegem o Estado democrático e constitucional de direito para o futuro. 
Muito embora exerça esta função de contrapeso, de equilíbrio, a Jurisdição Constitucional deve exercer sua função cercada de cuidados.

Como por exemplo, o cuidado em se estabelecer limites às decisões da Corte Constitucional para que não se fira a legitimidade do legislador constituinte originário, como também do legislador ordinário.

Ou seja, quando se exerce a capacidade interpretativa acerca do texto constitucional ou sobre a legislação ordinária, esta capacidade hermenêutica do conteúdo do texto constitucional não é sem limites. Nem poderia ser sem que houvesse consequências para a própria ordem constitucional que se procura manter.

Como destaca Manuel Aragón Reyes (2019, p. 05), num Estado constitucional os órgãos da Justiça Constitucional devem exercer jurisdição, não legislação.

Posto a questão desse modo, a democracia, aqui no sentido compreendido como democracia constitucional, só pode ser vista garantida quando é formalizada através da Constituição. Pois, que é a única forma de assegurar-se a soberania de um povo e impedir, por ela, que o Estado se volte contra a liberdade e igualdade de todos os cidadãos cotitulares desse poder soberano. Dito de outro modo, a democracia constitucional é o estabelecimento de regras de direito que limitam o poder constituído.

Neste ínterim, interessante são as lições de Manuel Aragón Reyes (2019, p. 09), vejase:

Esa es la base de la llamada «objeción democrática» a la justicia constitucional, al menos en su vertiente más simple, aunque también se haya extendido otra (cuyo origen, más que en Schmitt, está en Lambert) que, aceptando que la justicia constitucional es justicia y no política, discute la legitimidad de que unos jueces puedan controlar al legislador democrático, ya que entonces son aquellos los que «gobiernan» y no los representantes del pueblo, subvirtiendo de ese modo la división de poderes².

Ou seja, não é prudente adotar neste ponto a visão de Carl Schmitt sobre o caráter político da Constituição, volta-se, outrossim, à Hans Kelsen, que defende o caráter jurídico da Justiça Constitucional e que deve fato ela deve possuir.

\footnotetext{
${ }^{2}$ Em tradução livre: Essa é a base da chamada "objeção democrática" à justiça constitucional, pelo menos em seu aspecto mais simples, embora outra também tenha se espalhado (cuja origem, mais do que em Schmitt, está em Lambert) que, aceitando essa justiça constitucional é justiça e não política, discute-se a legitimidade de que alguns juízes podem controlar o legislador democrático, desde então, são aqueles que "governam" e não os representantes do povo, subvertendo a divisão de poderes.
} 
Dessarte, a crescente importância política dos tribunais tem não apenas se tornado mais abrangente, mas também se expandido em escopo, transformando-se assim um fenômeno diverso, multifacetado, que vai muito além do conceito que se tornou corrente, de declaração de políticas públicas por juízes, pois houve uma remarcação de fronteiras entre órgãos do estado (HIRSCHL, 2006, p. 03).

Como explica Mauro Cappelletti (1992, p. 67) há dois grandes tipos de sistemas de controle judicial da legitimidade constitucional das leis:

O sistema difuso, isto é, aquele em que o poder de controle pertence a todos os órgãos judiciários de um dado ordenamento jurídico que o exercitam incidentalmente, na ocasião da decisão das causas de sua competência; e o sistema concentrado em que o poder de controle se concentra ao contrário em um único órgão judiciário.

No direito brasileiro o controle de constitucionalidade será concentrado, ou seja, exercido pelo órgão de cúpula com competência originária, mas também incidental, difuso, em qualquer juízo, posto que se discute a questão de constitucionalidade como questão prejudicial ao objeto principal da lide.

Dessarte, estes mecanismos de controle de constitucionalidade, concretamente exercidos pela Corte Constitucional, são frequentemente chamados a resolver uma série de problemas, como por exemplo, extensão das liberdades de culto religioso e de expressão, dos direitos à igualdade e a privacidade da liberdade de reprodução, às políticas públicas relacionadas a justiça criminal, ao processo eleitoral, à propriedade, ao comércio, à educação, à imigração, ao trabalho e à proteção ambiental (HIRSCHL, 2006, p. 03).

O "problema" mais concretamente verificável relaciona-se a judicialização da política, como expansão da competência dos tribunais constitucionais, envolvendo direitos constitucionais de demarcação dos limites entre órgãos do estado (separação de poderes, federalismo).

Um exemplo atual é a decisão proferida em medida cautelar na ADI 6341, de relatoria do ministro Marco Aurélio, posto:

(...) ser o tema da saúde reservado, como gênero, à competência comum da União, dos Estados, do Distrito Federal e dos Municípios, a teor do artigo 23, inciso II, da Constituição Federal. (...) Deferiu-se, em parte, a medida acauteladora, para tornar explícita, no campo pedagógico e na dicção do Supremo, a competência concorrente ${ }^{3}$.

\footnotetext{
${ }^{3}$ BRASIL. Supremo Tribunal Federal. Medida Cautelar na Ação Direta de Inconstitucionalidade ${ }^{\circ}$ 6.341/ DF. Relator: Ministro Marco Aurélio. DJe: 24/03/2020.
} 
Outro exemplo, a Ação Declaratória de Constitucionalidade número 43, do Distrito Federal, de relatoria do ministro Marco Aurélio, que assentou a constitucionalidade do artigo 283 do Código de Processo Penal.

Como explana Giancarlo Rolla (2001, p. 06):

Em este sentido, no se puede afirmar que la ya dilatada experiencia de los Tribunales Constitucionales haya demostrarlo en la práctica que esta institución venga a distorsionar el sistema, sino muy al contrario, há venido a corroborar su operatividad dentro del mismo, brindando um nuevo soporte de legitimidad en el ejercicio del poder, a las fuerzas sociales que lo ejercen ${ }^{4}$.

Como se percebe, o papel da Justiça Constitucional encontra abrigo sob diversos vieses. Manter essa estrutura de democracia constitucional será o grande desafio pelo qual se desponta analisar neste estudo. Pois, faz parte da Jurisdição Constitucional assegurar voz aos menos desfavorecidos, contra a vontade de outros grupos que pretendam passar por cima de seus direitos ou subjugá-los.

Aponta-se aqui a visão de Jon Rawls, em seu livro "Uma teoria da justiça", e uma antítese sob a visão de Jürgen Habermas, em seu livro "A inclusão do outro, estudos de teoria política".

O papel da Justiça Constitucional, inclusive, tem assento na visão traçada por Yascha Mounk, em seu livro intitulado "O povo contra a democracia", de defender o Estado de direito contra o populismo, contra a reivindicação da representação exclusiva do povo, da relutância em tolerar a oposição e respeitar a necessidade de instituições independentes, que se colocam em rota de colisão contra a democracia constitucional.

\section{VINCULAÇÃO DOS PRECEDENTES JUDICIAIS E A JURISDIÇÃO CONSTITUCIONAL}

Por seu turno o legislador constituinte originário criou mecanismos por meio dos quais se possa controlar os atos normativos, verificando-se sua adequação aos preceitos previstos na Constituição Federal.

\footnotetext{
${ }^{4}$ Em tradução livre: Nesse sentido, não se pode dizer que a vasta experiência do Tribunal Constitucional tenha demonstrado, na prática, que essa instituição distorce o sistema, de uma maneira muito diferente, corroborando sua operação, nele oferecendo novo apoio, de legitimidade no exercício do poder, com as forças sociais que exerce.
} 
Trata-se do princípio da supremacia da Constituição, como descreve José Afonso da Silva (2016, p. 47-49), que significa que a Constituição se coloca no vértice do sistema jurídico do país, a que confere validade e que todos os poderes estatais são legítimos na medida em que ela os reconheça e na proporção por ela distribuídos.

O importante de se compreender o instituído sistema de precedentes, pelo Código de Processo Civil brasileiro, está na compreensão do valor vinculante das decisões auferidas em sede de controle de constitucionalidade, e de modo especial, o controle abstrato e concreto, previstos em seu art. 927.

Segundo as lições de Guilherme Rizzo do Amaral (2017, p. 01), os precedentes judiciais possuem em sua natureza a densificação de normas a partir da compreensão de um caso e suas circunstâncias fáticas e jurídicas. Senão veja-se:

In general, when someone refers to judicial precedent the immediate ideia that
comes to mind is that of the judges or courts duty to follow or obey previous
decisions from higher courts or from the same court. That, however, does not
answer the question about wicht previous decisions actually have, or should have,
this power over decision-makers. And et one should not mistake a precedent for the
actual decision from which it originates. The precedent has to be extracted from the
deciosn by the interpreter - more specifically, by the subsequent court (or decision-
maker0 which will apply the precedente - through the process of identifying the
ratio decidendi and separating it from obiter dicta ${ }^{5}$.

A doutrina do stare decisis, com o advento da Lei $\mathrm{n}^{\circ} 13.105 / 2015$, que estatuiu o novo Código de Processo Civil brasileiro, passou a alimentar amplo debate, tanto que no RE 655.265/DF, o ministro Edson Fachin assevera da seguinte forma:

[...] conclusão corroborada pelo Novo Código de Processo Civil, especialmente em seu artigo 926, que ratifica a adoção - por nosso sistema - da regra do stare decisis, que densifica a segurança jurídica e promove a liberdade e a igualdade em uma ordem jurídica que se serve de uma perspectiva lógico-argumentativa da interpretação ${ }^{6}$.

\footnotetext{
${ }^{5}$ Em tradução livre: Em geral, quando alguém se refere ao precedente judicial, a ideia imediata que vem à mente é a de que os juízes ou tribunais devem seguir ou obedecer a decisões anteriores de tribunais superiores ou do mesmo tribunal. Isso, no entanto, não responde à pergunta sobre o fato de que decisões anteriores realmente têm, ou deveriam ter, esse poder sobre os tomadores de decisão. E não se deve fazer um precedente para a decisão real da qual se origina. O precedente deve ser extraído da decisão pelo intérprete - mais especificamente, pelo tribunal subsequente (ou tomador de decisão) que aplicará o precedente - através do processo de identificação da ratio decidendi e separando-a de obiter dicta.

${ }^{6}$ BRASIL. Supremo Tribunal Federal. Recurso Extraordinário: RE 655.265/DF. Relator: Ministro Luiz Fux. DJe: 13/04/2016. Disponível em: http://redir.stf.jus.br/paginadorpub/paginador.jsp?docTP=TP\&docID=11465268. Acessado em: 25/06/2020.
} 
Em verdade, a regra do stare decisis é muito mais densa do que isso, de modo que não se pode concluir haver intersecção entre os sistemas do common law, com os de tradição civil law, ao qual se filia o sistema brasileiro.

Como apregoa Teresa Arruda Alvim Wambier (2012, p. 20) que a característica principal do common law é ter "casos como fonte do direito".

Dessarte, Guido Fernando Silva Soares (1999, p. 32-53) esclarece que a primeira acepção de common law, que é direito comum, deriva das sentenças judiciais emanadas dos tribunais de Westminster, cortes constituídas pelo rei e a ele subordinadas. Um outro sentido de common law apontado é aquele do direito criado pelo juiz, judge-made law, oposto ao statute law. Ou seja, embora o case law (precedente) seja a principal fonte do direito, ele pode ser modificado pela lei escrita; trata-se do case que foi reversed by statute, que lhe hierarquicamente superior. Outrossim, num sentido mais amplo, refere-se ao common law como um sistema de família de direitos influenciados pelo direito da Inglaterra, e contrates com o sistema da família romano-germânico que se denomina civil law.

Assim, a elementar do stare decisis (precedente) pode ser explicado pelo adágio: "stare decisis et non quieta movere". Alvejando o significado: as coisas decididas devem permanecer firmes e imodificáveis em razão das decisões (ABBOUD, p. 307).

São assas as palavras de Saul Brenner e Harold Spaeth (2017, p. 01) que dizem:

[...] Stare decisis es una versión abreviada de la frase latina stare decisis et non quieta movere, [...]. Puede tomar dos formas: stare decisis vertical o stare decisis horizontal. La primeira se refiere a la obligación que los jueces de tribunales inferiores tienen de adherise a los precedentes de tribunales superiores dentra la misma jurisdicción. La stare decisis horizontal concierne al deber de concordancia de un tribunal hermano, en caso de existir alguno ${ }^{7}$.

Neste diapasão há divergência nesta "commonlização" em parte da doutrina nacional. Por todos, Lenio Luiz Streck (2018, p.15), que sustenta que transformar o direito num sistema de precedentes e teses é equivocado, pois não há amparo nem no Código de Processo Civil, muito menos na Constituição Federal de $1988^{8}$.

Doutra banda, Luiz Guilherme Marinoni, Sérgio Cruz Arenhart e Daniel Mitidiero (2015, p. 150-151), destacam que aos Tribunais de Justiça e aos Tribunais Federais cabem a

\footnotetext{
${ }^{7}$ Em tradução livre: [...] stare decisis é uma versão abreviada da frase latina stare decisis et non quieta movere, [...]. Pode assumir duas formas: stare decisis vertical ou stare decisis horizontal. A primeira refere-se à obrigação de os juízes dos tribunais inferiores aderirem aos precedentes dos tribunais superiores dentro da mesma jurisdição. O stare decisis horizontal diz respeito ao dever de concordância de um tribunal irmão, se houver.

${ }^{8}$ Este ponto de vista também é enfrentado por Georges Abboud em seu "Processo Constitucional Brasileiro".
} 
jurisprudência, ou seja, a produção reiterada e unívoca emanada desses tribunais. Estes tribunais são denominados pelos autores de Cortes de Justiça. Entretanto, somente ao Supremo Tribunal Federal e ao Superior Tribunal de Justiça, ou como descreve os autores, às Cortes Supremas, cabem a produção dos precedentes.

Com este ângulo, calha observar o que diz Lenio Luiz Streck (2018, p.15, 17):

Típica importação acrítica do elemento central do common law. Resultado: em vez de interpretação de leis e casos, tudo se resumirá à aplicação de teses feitas por Cortes de Vértice. [...] face à ausência de racionalidade na aplicação das leis, parcela de processualistas passaram a defender a tese de que o novo CPC se abriu para a commonlização do Direito.

Não se pode conjecturar que somente aos tribunais estaduais e federais cabem a função de decidir, enquanto ao Supremo Tribunal Federal e ao Superior Tribunal de Justiça reserva-se a função de interpretação do direito e o seu sentido.

Porém, o controle exercido pela jurisdição constitucional é tanto mais forte nos dos enunciados sumulares vinculantes, do que aos "precedentes" estatuídos pela legislação processual, nos demais incisos do art. 927. Posto que a tese, nestes últimos casos, não possui o condão de vincular compulsoriamente os órgãos da Administração Pública em geral ${ }^{9}$.

Posto, não seria outro o escopo de qualquer julgamento por parte dos tribunais estaduais e federais, que o desiderato, também, de se preocuparem com a integridade da jurisprudência e o controle de constitucionalidade das leis.

Aliado a tais argumentos iniciais, importante evidenciar os elementos fundamentais para a criação do precedente no common law. Como explica Rupert Cross e J.W. Harris (1977, p. 76) todo precedente terá uma ratio decidendi:

[...] of case is any rule of law expressly or impliedly treated by the judge as a necessary step in reaching his conclusion, having regard to the line of reasoning adopted by him, or a necessary part of his Direction to the jury. [...] the expression ratio decidendi is used in two senses: (i) the rule of law for which a case is binding authorith, and (ii) the rule of law to be found in the actual opinion of the judge, forming the basis of his decision ${ }^{10}$.

\footnotetext{
${ }^{9}$ Como explicam André Ramos Tavares e Renato Gugliani Herani, a EC 45/04 "silenciou a respeito no caso da repercussão geral (e por tabela, também os demais incisos do art. 927 do CPC), (...), foi expressa a EC ao vincular o enunciado da súmula vinculante "aos demais órgãos do Poder Judiciário e à Administração Pública direta e indireta, nas esferas federal, estadual e municipal" (art. 103-A, CB/88". TAVARES, André Ramos; HERANI, Renato Gugliano. Direito Processual Constitucional: como técnica e como poder. In: ; GAMA, Marina Faraco Lacerda. Um Código de Processo Constitucional para o Brasil. Belo Horizonte: Arraes Editores, 2021. p. 4-48.

${ }^{10}$ Em tradução livre: [...] do caso é qualquer regra legal ou implícita tratada pelo juiz como um passo necessário para chegar a sua conclusão, tendo em conta a linha de raciocínio adotada por ele, ou uma parte necessária da sua direção ao júri. [...] a expressão ratio decidendi é usada em dois sentidos: (i) o estado de direito pelo qual um
} 
Note que em toda discussão em torno da doutrina dos precedentes se deve levar em conta as formas de controle de constitucionalidade, ou como explica Konrad Hesse (1998. p. 26), a jurisprudência constitucional, e nesse particular não pode olvidar de sua integridade na resposta unívoca sobre questão que verse a própria Constituição, razão pela qual criar, o legislador constituinte originário, mecanismos que possibilitam o controle destas questões.

Outrossim, nesta concepção de uma doutrina de precedentes, decorre o obter dictum, que pode ser definido da seguinte forma (CROSS, HARRIS, p. 80):

\begin{abstract}
Is it possible to say more with regard to an obter dictum than that it is proposition of law which does not form parto $f$ the ratio decidenti? The foregoing discussion of the ratio decidendi suggests that the answer to this question is 'no'. [...] obter dictum is a statement of law in the opinion which could not logically be a major premiss of the select facts of the decision ${ }^{11}$.
\end{abstract}

Ou seja, os obter dictum são pronunciamentos ou declarações a despeito da discussão de direito, que não poderiam logicamente ser uma premissa principal dos fatos selecionados das razões principais da decisão, porém possuem poder de persuasão no julgamento de casos e controle de constitucionalidade.

Outro elemento destacável na teoria dos precedentes é o distinguishing. No Código de Processo Civil, em seu artigo 489, parágrafo primeiro, inciso VI, se previu e considerou-se não fundamentada a decisão que "deixar de seguir enunciado de súmula, jurisprudência ou precedente invocado pela parte, sem demonstrar a existência de distinção no caso em julgamento ou a superação do entendimento" ${ }^{\prime 2}$.

Um último elemento crucial atinente ao sistema de precedentes do common law é o chamado overruling. Trata-se da modificação de entendimento pelo tribunal, na ratio decidendi contida no precedente por ele emitido. No entanto, como apregoa Lucas Buril de Macedo, para que se proceda a superação de um precedente judicial, as razões que ensejam sua mudança devem ser aprioristicamente superiores e mais fortes das que a ensejam sua continuidade (MACÊDO, 2017, p. 685).

caso é vinculativo, e (ii) o estado de direito a ser encontrado na própria opinião do juiz, formando a base de sua decisão

${ }^{11}$ Em tradução livre: É possível dizer mais em relação obter dictum do que proposição de lei que não faz parte da ratio decidenti? A discussão anterior sobre a ratio decidendi sugere que a resposta a essa pergunta é "não". [...] obter dictum é uma declaração de direito na opinião que não poderia logicamente ser uma premissa principal dos fatos selecionados da decisão.

${ }^{12}$ BRASIL. Lei Federal no. 13.105, de 16 de março de 2015. Código de Processo Civil, Brasília, DF, 2015. Disponível em: <http://www.planalto.gov.br/ccivil_03/_Ato2015-2018/2015/Lei/L13105.htm>. Acesso em: 25 jun. 2020. 
A despeito da análise desses elementos essenciais do sistema de precedentes do common law, pode-se destacar que proteção da ordem jurídica constitucional é erigida pelo Código de Processo Civil de 2015, seja pelos seus valores, simplificação de procedimentos e eliminações de complexidades, seja pelo fortalecimento das decisões judiciais proferidas nos tribunais e pela necessidade de manutenção íntegra da jurisprudência, e sobretudo da jurisprudência constitucional (ARAÚJO, 2016, p. 245) emanada em sede de controle difuso e concentrado de constitucionalidade previstos no art. 927, I, II, III e V do CPC. Assim, calha observar os apontamentos de Georges Abboud (2016, p. 311). Veja-se:

\footnotetext{
Portanto, não há aplicação mecânica ou subsuntiva na solução dos casos mediante a utilização do precedente judicial. Do contrário, não será decisão por precedente. Em outros termos, não existe uma prévia e pronta regra jurídica apta a solucionar por efeito cascata diversos casos futuros, pelo contrário, a própria regra jurídica (precedente) é fruto de intenso debate e atividade interpretativa, e, após ser localizada, passa-se a verificar se na circunstância do caso concreto que ela virá solucionar é possível utilizá-la sem que ocorram graves distorções, porque se elas ficarem caracterizadas, ela, isto é, o precedente, deverá ser afastada.
}

Tem-se aqui duas situações cruciais para os precedentes. Uma diz que o precedente não pode ser aplicado de maneira lógica-subsuntiva. Ou seja, a decisão proferida pelo tribunal em sede de um precedente não deverá formular uma súmula, porém conter a ratio decidendi aplicável a outros casos semelhantes.

Entretanto, veja-se que a estrutura do precedente do common law não é criada para aplicação futura.

Doutro modo, aos casos futuros que porventura vierem ser aplicados a ratio decidendi encontrada nos casos anteriores, não ocorreria de modo diverso ao que se compreende pela aplicação do precedente. Havendo, se for o caso, seu afastamento caso necessário, pelo distinguishing.

Entretanto, como destaca Georges Abboud (2016, p. 312), a vantagem desse modelo de sistema de precedentes é que eles não engessam o sistema jurídico. Muito ao contrário. $\mathrm{O}$ juízo não deve ser submisso a ele, razão pela qual deve encontrar sua aplicação pelo exercício da racionalização da fundamentação.

\section{OBTER DICTA COMO PRONUNCIAMOS ILÉGITIMOS}


Superada a preleção sobre doutrina dos precedentes, algumas considerações ainda se tornam importantes antes de se seguir com o estudo dos pronunciamentos ilegítimos pela corte constitucional em sede de obter dicta, no exercício da Jurisdição Constitucional.

Quando se utiliza o termo obter dicta, que no bojo da doutrina dos precedentes significa todos os pronunciamentos judiciais que não compuseram as razões principais da decisão judicial, refere-se à todas as discussões operadas em sede de processo objetivo de controle de constitucionalidade exercidos pela Justiça Constitucional.

Ou seja, a crítica que se procura aqui demonstrar está relacionada aos pronunciamentos judiciais especialmente desenvolvidos pela Corte Constitucional fora do processo objetivo. Isto porque, o papel da Corte Constitucional não é o de interferir nas decisões de outros órgãos ou mesmo influir na decisão de outros juízos.

Se o obter dicta pode ser compreendido como todos os pronunciamentos e debates acerca do amadurecimento das razões de decidir, qualquer intenção da Corte Constitucional, em especial dos membros que a compõe, no sentido de interferir em processos políticos ou jurídicos em outras instituições ou juízo, viola a ordem jurídica constitucional.

Como destaca Thomas da Rosa de Bustamante (2018, p. 05):

(...) doutrina estrita do stare decisis, que se tornou dominante no common law por influência do positivismo jurídico de Jeremy Bentham, no século XIX. Um dos elementos centrais dessa doutrina é a asserção de que nem todas as afirmações de um juiz ou uma corte possuem a autoridade própria dos precedentes judiciais, na medida em que é somente a ratio decidendi que vincula os juízes posteriores. Por mais importantes que os obiter dicta sejam, eles nunca são mais do que uma autoridade persuasiva.

Para efeito de se estabelecer a ilegitimidade dos pronunciamentos judiciais, tem-se que analisar em quais situações o tribunal pode comprometer, de forma autoritária, o funcionamento de outras instituições.

Num período pelo qual o Brasil passa por uma grande ebulição, polarização política, impasses funcionais e discursos vacilantes entre os poderes de Estado, esses pronunciamentos são particularmente perigosos. À guisa de exemplo dos tipos de perigos, o lançamento de fogos de artifício em direção ao prédio do Supremo Tribunal Federal por manifestantes pró governo federal ${ }^{13}$.

${ }^{13} \mathrm{In}:$ https://www1.folha.uol.com.br/poder/2020/06/apos-desmonte-de-acampamento-pro-bolsonaromanifestantes-lancam-fogos-de-artificio-contra-o-stf.shtml, acessado em 25/06/2021. 
Assim, interessante é a divisão operada por Thomas da Rosa de Bustamante (2018) em classificar os pronunciamentos judiciais abusivos, no sentido de ter-se (i) obter dicta em sentido estrito, que se dividem em (a) politicamente indutivos e os (b) abusivos transprocessuais; (ii) os obter dicta exoprocessuais, que se dividem em (a) prejulgadores e indutivos e (b) de competição interna; e os (iii) obter dicta em sentido impróprio.

Com relação ao item (i), estes são assim classificados pela sua capacidade de interferir indiretamente na atuação de outros agentes públicos, no qual se esperaria do judiciário uma posição de árbitro imparcial. No subitem (a) pode-se classificar como os pronunciamentos judiciais sobre o mérito de uma determinada matéria que esteja em discussão no Poder Legislativo. Dado que ao poder judiciário não deve apresentar sua interpretação do texto legislativo antes de sua conclusão e deliberação.

Ou seja, pressupõe a preservação do princípio de tripartição dos poderes e o equilíbrio entre as forças políticas, o que de outro lado seria uma clara violação ao Estado de Direito.

Quanto ao subitem (b), o pronunciamento é ilegítimo porque busca interferir no julgamento de um outro caso cujo julgamento está pendente em um outro órgão jurisdicional diferente. O obter dicta transprocessual é abusivo, pois viola e pretende influir sobre outro juízo, muitas vezes do mesmo tribunal, o que prejudica a qualidade do debate na instância apropriada.

Ao item (ii) diz-se obter dicta exoprocessual aqueles prolatados fora dos autos, através de um pronunciamento público e oficial, cuja relevância não está em função do seu conteúdo, mas primordialmente em função de sua origem.

Dado ao grau de influência na opinião pública sobre o julgamento do Supremo Tribunal Federal, e o alto grau de exposição pública de seus ministros, críticas às decisões dos colegas, prognóstico de decisões futuras, entrevistas sobre processos constituem uma forma ilegítima de pronunciamentos judiciais.

Aqui um exemplo claro é a manifestação do ministro Celso de Mello, do STF, que comparou o Brasil à Alemanha de Hitler, e disse que os "bolsonaristas" querem a abjeta ditadura. 
Hindenburg como chanceler da Alemanha, não hesitou em romper e em nulificar a progressista, democrática e inovadora Constituição de Weimar, impondo ao país um sistema totalitário de Poder". ${ }^{14}$

Já em seu subitem (a) ocorre um julgamento prévio, publicamente manifestado sobre a matéria que de fato ou de direito virá, quase certamente, a ser apreciada pelo tribunal ou magistrado que realiza este tipo de pronunciamento. Acaba ocorrendo uma manifesta espécie de conselho para que o jurisdicionado ingresse em juízo pedindo determinado controle ou providência, que será apreciado pelo tribunal num momento futuro.

No subitem (b) o pronunciamento ilegítimo ocorre de forma torpe, uma investida de um magistrado (ministro) buscando exercer pressão sobre o outro, com vistas a minar sua autoridade em relação à decisão ou contribuir para a revisão do seu posicionamento.

Por último, no item (iii), a nota típica da ilegitimidade do pronunciamento, vez possuir publicidade, oficialidade e relevância institucional, não está, neste tipo de pronunciamento, na interferência em decisões atuais ou posteriores de um tribunal. A ilegitimidade está na própria interpretação do direito à circunstância do julgamento do caso, como por exemplo, o magistrado (ministro) realizar juízo moral involuntariamente.

Ao fim ao cabo, percebe-se que os pronunciamentos judiciais ilegítimos possuem o condão interferir na integridade da Jurisdição Constitucional e da democracia constitucional, como também sobre as decisões emanadas em sede de controle concentrado e difuso de constitucionalidade.

\section{À GUISA DE CONCLUSÃO}

Através das proposições colocadas neste estudo, insere-se a temática da Jurisdição Constitucional, cuja atividade recai sobre todo poder judiciário, e de modo especial ao Supremo Tribunal Federal, que exerce no Brasil o papel de Corte Constitucional.

As decisões dos tribunais possuem um objetivo claro de concretizar interesses socialmente relevantes, fundamentais, imbricados na Constituição. Entretanto, a convivência da Jurisdição Constitucional com a Democracia Constitucional, requer por parte dos magistrados ou ministros, uma postura reservada atinente a importância e a seriedade que o

\footnotetext{
${ }^{14}$ Ministro Celso de Mello in: https://www1.folha.uol.com.br/colunas/monicabergamo/2020/05/celso-de-mellocompara-brasil-a-alemanha-de-hitler-e-diz-que-bolsonaristas-querem-abjeta-ditadura.shtml. Acessado em $25 / 06 / 2021$
} 
processo decisório possui na efetivação da Jurisdição Constitucional, e como forma de preservação dos valores e princípios da própria Constituição.

Dado não podermos estabelecer dicotomias entre os sistemas de controle de constitucionalidade dentro da ordem jurídica brasileira, a convivência dos modelos difusos e concentrado, sob a ótica dos precedentes judiciais, e as funções complexas que a Corte Constitucional possui, exigem novos desafios.

O sistema de Justiça Constitucional deve ser integral para conceber a ilegitimidade das leis, atos administrativos, eventos políticos, processos eleitorais, tratados, ou mesmo de lei de reforma constitucional.

O papel da Jurisdição Constitucional na preservação dos princípios e valores imbrincados na Constituição Federal, seja na manutenção da ordem democrática, federativa, exigem uma postura sóbria no exercício de suas competências para que haja harmonia e não se extrapole as competências da própria Corte Constitucional.

A construção de mecanismos e instrumentos aptos a dar coerência ao controle de constitucionalidade pelos tribunais, consolida sua função de vinculação, o que é importância na consolidação da supremacia da Constituição.

Desta forma, é pernicioso admitir a produção de pronunciamentos ilegítimos como fenômenos capazes de arranhar o modelo do Estado Democrático de Direito. Razão pela qual tentou-se demonstrar o significado da Justiça Constitucional, o seu papel e a convivência dos sistemas de controle de constitucionalidade, com o modelo de vinculação das decisões judiciais erigidos pelo Código de Processo Civil de 2015, para demonstrar-se a importância e o problema da falta de legitimidade de um poder do Estado em controlar os atos dos demais poderes, sob a ótica da consolidação e vinculação das decisões judiciais em sede de controle difuso e concentrado de constitucionalidade.

\section{REFERÊNCIAS BIBLIOGRÁFICAS}

ALVIM, Eduardo Arruda; et al. Processo Constitucional. São Paulo: Editora Revista dos Tribunais, 2014.

ABBOUD, Georges. Processo constitucional brasileiro. São Paulo: Editora Revista dos Tribunais, 2016. 
Discricionariedade administrativa e judicial: o ato administrativo e a decisão judicial. São Paulo: Revista dos Tribunais, 2014.

AMARAL, Guilherme Rizzo. Judicial precedente and arbitration. Are arbitrators bound by judicial precedent? London: Wild, Simmonds \& Hill Publishing, 2017.

ARAÚJO, Fabio Caldas de. Curso de processo civil: parte geral. Tomo I. São Paulo: Malheiros, 2016.

TAVARES, André Ramos; HERANI, Renato Gugliano. Direito Processual Constitucional: como técnica e como poder. In: ; GAMA, Marina Faraco Lacerda. Um Código de Processo Constitucional para o Brasil. Belo Horizonte: Arraes Editores, 2021.

BRENNER, Saul; SPAETH, Harold J. Stare Indecisis. Las alteraciones del precedente em la Corte Suprema de Estados Unidos, 1946-1992. Traducción: Sebastián Figueroa Rubio y Camila Spoerer Grau. Madrid: Marcial Pons, 2017.

BRASIL. Supremo Tribunal Federal. Medida Cautelar na Ação Direta de Inconstitucionalidade n 6.341/ DF. Relator: Ministro Marco Aurélio. DJe: 24/03/2020.

Lei Federal no. 13.105, de 16 de março de 2015. Código de Processo Civil, Brasília, DF, 2015. Disponível em: <http://www.planalto.gov.br/ccivil_03/_Ato20152018/2015/Lei/L13105.htm>. Acesso em: 25 jun. 2020.

Jornal Folha de São Paulo. Disponível em: https://www1.folha.uol.com.br/colunas/monicabergamo/2020/05/celso-de-mello-comparabrasil-a-alemanha-de-hitler-e-diz-que-bolsonaristas-querem-abjeta-ditadura.shtml. Acessado em $25 / 06 / 2020$.

BUSTAMANTE, Thomas da Rosa de. Obiter dicta abusivos: esboço e uma tipologia dos pronunciamentos judiciais ilegítimos. Revista Direito GV. V. 14. São Paulo, maio-ago, 2018.

CAPPELLETTI, Mauro. O controle judicial de constitucionalidade das leis no direito comparado. 2 ed. Trad. Aroldo Plínio Gonçalves. Porto Alegre: Sergio Antonio Fabris Editor, 1992.

CROSS, Rupert; HARRIS, J. W. Precedent in English Law. Third Edition. Oxford: Clarendon Press, 1977.

HERANI, Renato Gugliano. A prova da inconstitucionalidade. Curitiba: Editora Prismas, 2015.

HESSE, Konrad. Elementos de Direito Constitucional da República Federal da Alemanha. Tradução: Luís Afonso Heck. Porto Alegre: Sergio Antonio Fabris Editor, 1998.

HIRSCHL, Ran. The new constitutionalism and the judicialization of pure politics worldwide. Fordham Law Review, v. 75, n. 2. 2006, trad. Diego Werneck Arguelhes; Pedro Jimenez Cantisano. 
LAMBERT, Edouard. Les Gouvernement des Juges et La Lutte contre la Législation Sociale aux États-Unis. Paris: Marcel Giard, 1921.

MACÊDO, Lucas Buril. O transplante jurídico de técnicas para aplicação de precedentes: análise específica da transformação (transformation), sinalização (signaling) e superação antecipada (antecipatory overruling). In: A nova aplicação da jurisprudência e precedentes no CPC/2015. Dierle Nunes et al (org.). São Paulo: Revista dos tribunais, 2017.

MARINONI, Luiz Guilherme; MITIDIERO, Daniel.; ARENHART, Sérgio Cruz. Novo Curso de processo civil: teoria do processo civil. São Paulo: Revista dos Tribunais, 2015. v. 1.

REYES. Manuel Aragón. El futuro de la Justicia Constitucional. Anuario Iberoamericano de Justicia Constitucional, 2019, v. 23.

ROLLA, Giancarlo. El papel de la Justicia Constitucional en el marco del constitucionalismo contemporáneo. Derecho PUCP, 2001.

RÜTHERS, Bernad; FISCHER, Christian; BIRK, Axel. Rechtstheorie: mit juristicher methodenlehre. 10. Auflage. Müchen: C. H. Beck oHG, 2018. p. 178.

SILVA, José Afonso. Curso de direito constitucional positivo. 39a ed. São Paulo: Malheiros, 2016.

SOARES, Guido Fernando Silva. Common Law: introdução ao direito dos EUA. São Paulo: Editora Revista do Tribunais, 1999.

STRECK, Lenio Luiz. Precedentes judiciais e hermenêutica. Salvador: Editora JusPodivm, 2018.

WAMBIER, Teresa Arruda Alvim; In: WAMBIER, Teresa Arruda Alvim (coord.). Direito Jurisprudencial. São Paulo: Editora Revista dos Tribunais, 2012.

ZANETI JR., Hermes. O valor vinculante dos precedentes: teoria dos precedentes normativos formalmente vinculantes. 2. ed. Salvador: JusPODVM, 2016. 